\title{
Intraluminal capsaicin does not affect fluid and electrolyte absorption in the human jejunum but does cause pain
}

\author{
J Hammer, H F Hammer, A J Eherer, W Petritsch, P Holzer, G J Krejs
}

\begin{abstract}
Background-Stimulation of sensory nerves with capsaicin regulates ion transport in the small intestine in animal experiments.

Aim-To investigate whether sensory nerves that are stimulated by capsaicin administration influence fluid and electrolyte absorption in the human jejunum in vivo.

Method-Intestinal perfusion studies were performed in 12 healthy subjects using a four lumen tube with a proximal occlusion balloon and a plasma-like electrolyte solution. After an initial control period, 5 $(\mathrm{n}=3), 10(\mathrm{n}=8)$, or $50(\mathrm{n}=1) \mu \mathrm{g} / \mathrm{ml}$ capsaicin was added to the perfusate, and this was followed by a final control period. Rates of absorption of water, sodium, potassium, chloride, and bicarbonate were determined in a $30 \mathrm{~cm}$ segment of jejunum using a non-absorbable volume marker.

Results-At all three concentrations of capsaicin there were no significant changes in water and electrolyte absorption as compared with control periods. Two subjects who received $10 \mu \mathrm{g} / \mathrm{ml}$ and the subject receiving $50 \mu \mathrm{g} / \mathrm{ml}$ experienced crampy abdominal pain.

Conclusion-The results do not support the hypothesis that capsaicin sensitive afferent nerves are involved in the physiological regulation of net absorption or secretion across the human jejunal mucosa. Chemical stimulation of these nerves, however, gives rise to abdominal pain.
\end{abstract}

(Gut 1998;43:252-255)

Internal Medicine IV, University of Vienna, Vienna, Austria

J Hammer

Department of Experimental and Clinical

Pharmacology,

University of Graz

P Holzer

Correspondence to: Dr H F Hammer, Associate Professor of Internal Medicine, Medizinische Universitätsklinik, Auenbruggerplatz 15, 8036 Graz, Austria.

Accepted for publication 25 February 1998

Keywords: capsaicin; sensory nerves; axon reflex; motility; jejunum

Sensory nerves in the gastrointestinal tract are involved in reflex regulation of various gastrointestinal functions. Reflexes are relayed through neurons in the central nervous system, in prevertebral ganglia, and in intramural nerve plexuses. ${ }^{1}$ An additional type of reflex regulation is an axon reflex-like mechanism, whereby release of transmitters from sensory nerve fibres causes direct stimulation of intestinal effectors. Afferent fibres involved in axon reflexes are mostly capsaicin sensitive unmyelinated C-fibres, ${ }^{2}$ which are present in both the vagus and splanchnic nerves and may regulate intestinal secretion, motility, and circulation. ${ }^{3}$

Involvement of sensory nerves in the regulation of intestinal secretion has been shown in various animal species. In these studies, sensory nerves were stimulated by electrical field or capsaicin. Chloride secretion in the ileum of the rabbit and guinea pig is enhanced by electrical field stimulation ${ }^{4-6}$ and by capsaicin. ${ }^{7}$ Capsaicin has also been shown to stimulate nutrient absorption in rats. ${ }^{8}$ It has been suggested that capsaicin sensitive nerves regulate ion transport in the gastrointestinal tract by release of neurotransmitters that activate submucosal secretomotor neurons. ${ }^{7}$ Capsaicin sensitive neurons have also been shown to mediate the pathological hypersecretion caused by Escherichia coli enterotoxin in the rat intestine ${ }^{9}$ and by Clostridium difficile toxin $\mathrm{A}$ in the rat ileum. ${ }^{10}$

In the human small intestine, capsaicin sensitive neurons have been shown to affect small intestinal motility in vitro, ${ }^{11-13}$ but there are no data on their effect on intestinal secretion and on their effects in vivo. The aim of this study was to test the hypothesis that luminal capsaicin administration increases chloride secretion in the human jejunum in vivo.

\section{Methods}

EXPERIMENTAL SUBJECTS

Studies were carried out in 12 healthy men, aged $20-36$, mean age 25 . They were recruited by public advertisement and none had a history of gastrointestinal disease or abdominal surgery other than appendectomy. All subjects gave written informed consent. The study was approved by the ethics committee of Karl Franzens University of Graz.
EXPERIMENTAL DESIGN AND PROCEDURE

For intestinal perfusion, a tube assembly (outer diameter $7 \mathrm{~mm}$ ) was used that consisted of five tubes that were bonded together with tetrahydrofuran (Sigma Chemical Corp, St Louis, Missouri, USA). One tube was connected to a balloon which was used to occlude the intestinal lumen proximal to the site of infusion. Three tubes were radio-opaque to allow fluoroscopic location of the assembly; their distal ends were immediately distal to the occluding balloon (perfusion site) and $30 \mathrm{~cm}$ and 60 $\mathrm{cm}$ distal to the balloon (sampling sites). The length of the test segment (between proximal and distal sampling site) was $30 \mathrm{~cm}$. An additional lumen was used to remove endogenous secretions proximal to the occluding balloon. 


Control Capsaicin
$\begin{aligned} & \text { Equilibration Test } \\ & \text { Start }\end{aligned}$
of experiment
Figure 1 Experimental design.

After a 12 hour fast, volunteers swallowed the tube assembly. The position of the assembly was confirmed by fluoroscopy. The infusion site was located at the ligament of Treitz. With the tube in the right position, the occluding balloon was inflated with $60 \mathrm{ml}$ of air and perfusion was started. None of the subjects experienced any sensation as the balloon was inflated. As shown in fig 1 , perfusion was performed for three 60 minute test periods, which were preceded by 30 minute equilibration periods. The first and the third test period were used as intraindividual controls. The second test period was used to assess the effect of capsaicin. During the equilibration periods the samples were discarded. During each of the control and test periods, samples were collected separately for three consecutive 20 minute periods.

A plasma-like electrolyte solution containing $135 \mathrm{mM}$ sodium, $5 \mathrm{mM}$ potassium, 110 $\mathrm{mM}$ chloride, $30 \mathrm{mM}$ bicarbonate, and $2 \mathrm{~g} / 1$ polyethylene glycol was perfused at an infusion rate of $10 \mathrm{ml} / \mathrm{min}$ using a peristaltic pump. The rate of aspiration at the two sampling sites was $1.5 \mathrm{ml} / \mathrm{min}$. During the capsaicin test period, $5(\mathrm{n}=3), 10(\mathrm{n}=8)$, or $50(\mathrm{n}=1)$ $\mu \mathrm{g} / \mathrm{ml}$ capsaicin (Sigma Chemical Corp) was added to the perfusate for 90 minutes - that is, a 30 minute equilibration and a 60 minute test period.

Intestinal samples were analysed for sodium, potassium, chloride, and bicarbonate (as total $\mathrm{CO}_{2}$ ) concentration using an automated analyser (Synchron Clinical System CX3; Beckman, Palo Alto, California, USA). Polyethylene glycol was determined by the method of Hyden. ${ }^{14}$ Absorption rates were calculated from the perfusion rate and the changes in polyethylene glycol and electrolyte concentrations in the test segment as previously reported. ${ }^{15}$

\section{STATISTICAL ANALYSIS}

Results are expressed as mean (SEM). For statistical analysis, unpaired two tailed Student's $t$ tests were performed. $\mathrm{p}<0.05$ was considered significant. A linear least squares regression analysis was performed to determine the difference in absorption/secretion between the control period and the test period.

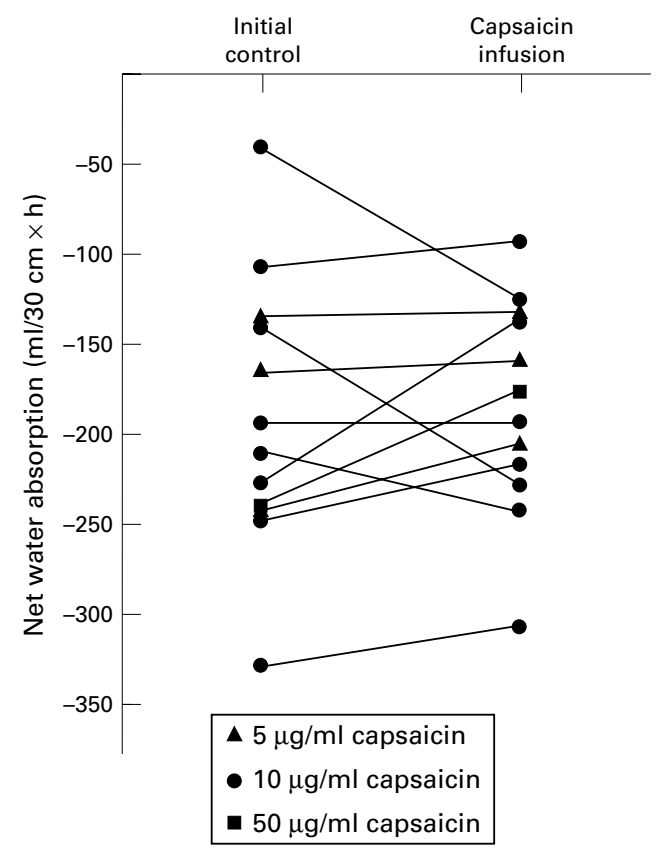

Figure 2 Absorption of water during the initial control period and during the test period for all capsaicin doses for each subject.

\section{Results}

Infusions of the control solution and the solutions containing 5 and $10 \mu \mathrm{g} / \mathrm{ml}$ capsaicin were generally well tolerated. Two volunteers receiving $10 \mu \mathrm{g} / \mathrm{ml}$ developed abdominal cramps at the end of the 60 minute test period. Cramps resolved within five minutes of the end of the capsaicin perfusion according to the protocol. When $50 \mu \mathrm{g} / \mathrm{ml}$ capsaicin was infused, the volunteer developed crampy abdominal pain within 20 minutes and pain persisted until the end of the 60 minute test period. Therefore no further studies were performed with this high capsaicin concentration. Cramps or abdominal discomfort did not develop during any of the control periods.

Table 1 shows that there were no changes in the rates of jejunal absorption of water, sodium, potassium, chloride, and bicarbonate during or after perfusion of $10 \mu \mathrm{g} / \mathrm{ml}$ capsaicin. Capsaicin at a concentration of $5 \mu \mathrm{g} / \mathrm{ml}$ also failed to affect jejunal absorption. Figure 2 shows individual data of absorption of water during the initial control period and during the test period for all capsaicin concentrations used. Individual changes in electrolyte absorption paralleled the changes in water movement (data not shown). Absorption values in the one subject in whom $50 \mu \mathrm{g} / \mathrm{ml}$ capsaicin was used were within the range of observations obtained with $10 \mu \mathrm{g} / \mathrm{ml}$ capsaicin.

Table 1 Effect of capsaicin infusion $(10 \mu \mathrm{g} / \mathrm{ml})$ on jejunal absorption of water and electrolytes from plasma-like electrolyte solution

\begin{tabular}{llll}
\hline & Initial control & Capsaicin infusion & Final control \\
\hline Net water movement $(\mathrm{ml} / 30 \mathrm{~cm} / \mathrm{h})$ & $-192(11)$ & $-201(8)$ & $-181(7)$ \\
Sodium $(\mathrm{mEq} / 30 \mathrm{~cm} / \mathrm{h})$ & $-24.2(1.6)$ & $-26.1(1.1)$ & $-22.2(1.0)$ \\
Potassium $(\mathrm{mEq} / 30 \mathrm{~cm} / \mathrm{h})$ & $-1.1(0.06)$ & $-1.1(0.04)$ & $-1.1(0.04)$ \\
Choride $(\mathrm{mEq} / 30 \mathrm{~cm} / \mathrm{h})$ & $-10.7(1.1)$ & $-13.1(0.7)$ & $-8.4(0.7)$ \\
Bicarbonate $(\mathrm{mEq} / 30 \mathrm{~cm} / \mathrm{h})$ & $-11.5(0.4)$ & $-12.0(0.3)$ & $-11.6(0.2)$ \\
\hline
\end{tabular}


To assess whether short term effects of capsaicin on absorption were missed by pooling the three 20 minute collections, we separately analysed the three 20 minute samples obtained during each of the capsaicin test periods. Electrolyte and water absorption in the first and third 20 minute collection period were not significantly different.

\section{Discussion}

The aim of the current study was to examine fluid and electrolyte transport after afferent neurons in the jejunum of healthy volunteers had been stimulated by topically applied capsaicin. With an in vivo infusion technique that has been validated for the assessment of absorption and secretion in humans in vivo, ${ }^{15-18}$ we failed to show any changes in electrolyte and water absorption by capsaicin. Thus in our model we were not able to extend the observations made in experimental animals to the human jejunum. It follows that, unlike in the guinea pig $^{7}$ and rat $^{9}{ }^{10}$ gut, capsaicin sensitive nerves in the human intestin $\mathrm{e}^{19}$ do not contribute to the physiological regulation of net absorption and secretion.

Although theoretically possible, we do not think that effects of capsaicin on mucosal function were missed as a consequence of the study design. Two points argue against the hypothetical possibility that the concentrations of capsaicin used in our study were too low to have an effect in human jejunum. Firstly, the capsaicin concentrations used in our study $(5-50 \mu \mathrm{g} / \mathrm{ml}=16-160 \mu \mathrm{M})$ were within the range of concentrations $(10-160 \mu \mathrm{M})$ that caused sensory nerve mediated vasodilation in the rat stomach. ${ }^{19}$ Secondly, the concentration of $50 \mu \mathrm{g} / \mathrm{ml}$ capsaicin, and, in two volunteers, $10 \mu \mathrm{g} / \mathrm{ml}$, caused a painful crampy sensation in the abdomen. Owing to the pain that $50 \mu \mathrm{g} / \mathrm{ml}$ capsaicin caused in one volunteer, further study of this and higher concentrations of the drug was not possible. It can be excluded that the pain was due to the volume effect of the infusion or intestinal distension by the occluding balloon since pain did not develop during the control periods preceding and following the capsaicin infusions.

Since comparison of the first 20 minute collection obtained during the capsaicin test period with the third 20 minute collection period did not show any differences in absorption, it is also unlikely that our study design missed any short lasting effects of capsaicin, given that the stimulant action of capsaicin on afferent neurons is rapidly desensitising. ${ }^{20}$

It is concluded therefore that capsaicin does not affect net water and electrolyte movement in the human jejunum, which contrasts with previously reported findings in animals. ${ }^{79} 10$ Capsaicin sensitive afferent neurons are hence unlikely to participate in the physiological control of electrolyte and fluid transport in the human small intestine. It remains to be determined, however, whether these neurons come into play under the pathological conditions of hypersecretion caused by bacterial toxins, as has been shown in animal experiments. ${ }^{9} 10$
Despite its ineffectiveness on secretion and absorption, intrajejunal capsaicin had a distinct action in that it caused abdominal discomfort and overt pain. This effect was concentration- and time-related, given that pain was felt only at the end of the capsaicin test period during two out of eight experiments with $10 \mu \mathrm{g} / \mathrm{ml}$ capsaicin but had already developed during the first third of the capsaicin test period and persisted until the end of the perfusion during the only experiment with $50 \mu \mathrm{g} / \mathrm{ml}$ capsaicin. The ability of intrajejunal capsaicin to give rise to pain was unexpected, since exposure of the rat gastric mucosa to 5-fold higher concentrations of capsaicin failed to evoke pseudoaffective reactions indicative of pain. ${ }^{21}$ On the other hand, the sensation of pain observed in the current study is consistent with the high algesic potency of capsaicin, which is due to its stimulant action on nociceptors. ${ }^{20}$ It is not possible to infer from the present findings whether capsaicin caused pain by directly stimulating nociceptive afferents in the intestinal mucosa or by stimulating motility $^{11}{ }^{12}$ as might be deduced from the crampy nature of the sensation. Stimulation of motility may result in pain from excessive contractions or movement of the inflated balloon along the intestine. Excessive contraction or distension of the gut is well established to give rise to pain, ${ }^{22}$ whereas chemical nociception in the intestine has been little studied. Future studies will have to evaluate the mechanisms by which capsaicin causes pain in the human jejunum.

1 Grundy D, Scratcherd T. Sensory afferents from the gastrointestinal tract. In: Wood JD, ed, Schultz SG, section ed. Handbook of physiology;section 6: the gastrointestinal system. Bethesda: American Physiological Society,
1989:593-620.

2 Szolscanyi J. Antidromic vasodilation and neurogenic inflammation. Agents Actions 1988;23:4-11.

3 Holzer P, Bartho L. Sensory neurons in the intestine. In: Geppetti P, Holzer P, eds. Neurogenic inflammation. Boca Raton: CRC Press, 1996:153-67.

4 Hubel KA. The effects of electrical field stimulation and tetrodotoxin on ion transport by the isolated rabbit ileum. $\mathcal{F}$ rodotoxin on ion transport by

5 Cook HJ, Shonnard K, Highison G, et al. Effects of neurotransmitter release on mucosal transport in guinea pig ileum. Am f Physiol 1983;245:G745-50.

6 Cook HJ. Influence of enteric cholinergic neurons on mucosal transport in guinea pig ileum. Am f Physiol 1984; 246:G263-7.

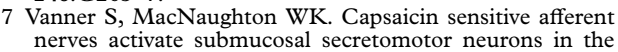
guinea pig ileum. Am f Physiol 1995;269:G203-9.

8 Udupihille $M$. The effect of capsaicin on the small intestinal absorption of glucose and alanine in the rat. Indian $\mathcal{F}$ Physiol Pharmacol 1993;37:59-62.

9 Nzegwu HC, Levin RJ. Luminal capsaicin inhibits fluid secretion induced by enterotoxin E. coli STa, but not by carbachol, in vivo in rat small intestine and large intestine. Exp Physiol 1996;181:313-15.

10 Castagliulo I, LaMont JT, Letourneau R, et al. Neuronal involvement in the intestinal effects of Clostridium difficile toxin A and Vibrio cholerae enterotoxin in rat ileum. Gastroenterology 1994;107:657-65.

11 Maggi CA, Patacchini R, Santicioli P, et al. Specific motor effects of capsaicin on human jejunum. Eur $\mathcal{F}$ Pharmacol 1988;149:393-5.

12 Maggi CA, Patacchini R, Santicioli P, et al. Human isolated small intestine: motor responses of the longitudinal muscle to field stimulation and exogenous neuropeptides. Archives of Pharmacology 1989;339:415-23.

13 Maggi CA, Patacchini R, Santicioli P, et al. Human isolated small intestine: motor responses of the circular muscle to field stimulation and exogenous neuropeptides. Archives of Pharmacology 1990;341:256-61.

14 Hyden SA. A turbidimetric method for the determination of higher polyethylene glycols in biological materials. Annals of the Royal Agricultural College Sweden 1956;22: Annals of

15 Petritsch W, Eherer AJ, Holzer-Petsche U, et al. Effect of cholera toxin on the human jejunum. Gut 1992;33:1174-8. 
16 Fordtran JS, Rector FC, Carter NW. The mechanisms of sodium absorption in the human small intestine. $\mathcal{F}$ Clin

17 Petritsch W, Holzer-Petsche U, Hinterleitner T, et al. Intravenous atrial natriuretic peptide does not affect water and ion transport in the human small intestine. Eur $\mathrm{f}$ Clin Invest 1989;19:272-7.

18 Reicht G, Petritsch W, Eherer AJ, et al. Absorption of hydrolysed bovine serum albumin from the human jejunum over a 6-hour period. Eur f Gastroenterol Hepatol 1997;9:81-5.
19 Holzer P, Lippe IT. Stimulation of afferent nerve endings by intragastric capsaicin protects against ethanol-induce damage of gastric mucosa. Neuroscience 1988;27:981-7.

20 Holzer P. Capsaicin: cellular targets, mechanisms of action, and selectivity for thin sensory neurons. Pharmacol Rev 1991;43:143-201.

21 Holzer P, Livingston EH, Saria A, et al. Sensory neurons mediate protective vasodilation in rat gastric mucosa. $A m \mathcal{F}$ Physiol 1991;260;G363-70.

22 Mayer EA, Gebhart GF. Basic and clinical aspects of visceral hyperalgesia. Gastroenterology 1994;107:271-93.

\section{Gut-http://www.gutjnl.com}

Visitors to the world wide web can now access Gut either through the BMJ Publishing Group's home page (http://www.bmjpg.com) or directly by using its individual URL (http://www.gutjnl.com). There they will find the following:

- Current contents list for the journal

- Contents lists of previous issues

- Members of the editorial board

- Subscribers' information

- Instructions for authors

- Details of reprint services.

A hotlink gives access to:

- BMJ Publishing Group home page

- British Medical Association web site

- Online books catalogue

- BMJ Publishing Group books

The web site is at a preliminary stage and there are plans to develop it into a more sophisticated site. Suggestions from visitors about features they would like to see are welcomed. They can be left via the opening page of the BMJ Publishing Group site or, alternatively, via the journal page, through "about this site". 